\title{
Comparison of Dentoalveolar Canting on Class I, II, and III Malocclusion Using Panoramic Radiography (Research Report)
}

\author{
Andres \\ Department of Orthodontic \\ Faculty of Dentistry, Universitas Sumatera Utara \\ Medan, Indonesia \\ andrestandean@gmail.com
}

\author{
Erna Sulistyawati \\ Department of Orthodontic \\ Faculty of Dentistry, \\ Universitas Sumatera Utara \\ Medan, Indonesia
}

\author{
Nazruddin \\ Department of Orthodontic \\ Faculty of Dentistry, Universitas Sumatera Utara \\ Medan, Indonesia
}

\begin{abstract}
Canting dentoalveolar is the slope of the teeth in the occlusal plane that is appears to everyone with different level. The sample was 60 adults were divided into three groups: 20 people skeletal Class I, 20 people skeletal Class II, and 20 people skeletal Class III. Canting dentoalveolar take from Nasal Line (NL) and Mandible Line (ML) to incisive central and first molar maxilla and mandible. Index value canting maxilla and mandible from derived height from region left and right maxilla and mandible using a Fisher's method on panoramic radiographs. The relationship between canting dentoalveolar and malocclusion Class I, II, and III was determined using Spearman correlation test. There are significant relationship between canting dentoalveolar and malocclusion Class I, II, and III. Dental canting can find in patient with skeletal Class I, II, and III. There is a significant relationship between the dental canting in patient with skeletal Class I, II, and III. Patient with malocclusion Class II and II have a greater degree of canting compared to patients with skeletal malocclusion Class I.
\end{abstract}

Keywords-skeletal malocclusion, canting dentoalveolar, canting maxilla and mandible

\section{INTRODUCTION}

The purpose of orthodontic treatment to restore the function, stability, and aesthetic faces as well as dental. Facial and dental aesthetics are the main reasons patients ask for orthodontic treatment. One of the things that affect is the symmetry factor of dentoalveolar [1].

The occlusal plain cant is the slope of the vertical relationship of the tooth along the occlusal plain measured on one side of the arch to the other. Canting the occlusal plain is present in every person but severe canting can be aesthetic problem. Severe canting occlusal plains will have aesthetic complaints [2].

Local factors that cause occlusion of occlusal dental plains loss were deciduous teeth, losing congenital teeth, and bad habits like finger sucking [2]. Based on previous research Nasila Nohadini states "canting classes I, II, and III have different cant dentoalveolar levels where canting levels in skeletal patients class II, and III greater than in skeletal patients class I". On this basis the authors wish to examine the differences in canting in patients with skeletal malocclusion Class I, Class II, and Class III.

\section{MATERIALS AND METHODS}

The population was taken from patients in RSGMP Specialist Clinic RSGMP FKG USU as many as 60 people and divided into 3 sub-divisions based on skeletal malocclusion class I, II, and III. Age range of the sample is 17-35 years old, considering the growth stage has been completed and the age range of young adults.

The samples chosen in this study were determined by the criteria for skeletal malocclusion class I, class II, and class III, good teeth on maxillary and mandible arch, both central and lateral incisors and maxillary and mandible first molars were complete, panoramic images in good condition and is performed in the same place with the same device, no orthodontic treatment has been performed, all permanent teeth complete without taking into account the presence or absence of third molars, no fixed denture, no history of oral trauma, no pathological abnormalities, no caries of the incisors central and lateral and maxillary and mandible first molars, no skeletal canting. The research procedure is as follows. Identify the number of teeth involved for canting measurement i.e. central and lateral incisors and maxillary and mandible first molars to be included in the sample.

Panoramic photographs were taken using the Asahi Roentgen, Auto Zero, Japan tools in the Pramita laboratoty for all samples under standard circumstances (Figure 1). Samples used in normal circumstances there is no skeletal canting therefore measurements will be made first by measuring the Ptm-Sp point between the 
left and right regions of the maxilla as well as measuring the Tgc-Gn point between the left and right regions of the maxilla.

Tracing panoramic photos was done on acetate paper with $0.5 \mathrm{~mm}$ pencil by one operator to avoid distortion or difference calculation when tracing is done. Then identify the point and size of the distance is -NL, ms-NL, isa-NL, msa-NL, ii-ML, mi-ML, iia-ML, mia-ML, ii-MLa, iia-MLa (Figure 1).

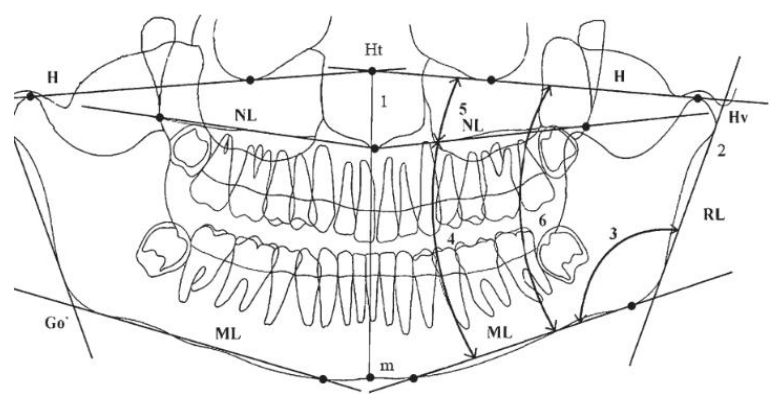

Figure 1. Identify the dots on the panoramic photo [4].

Measurement of the occlusal plain canting on each sample is the difference between left and right distance, measured from is, ms, isa, msa, ii, mi, iia, mia, ii, iia to plain NL, ML, and MLa. The difference in left and right values that did not differ significantly with the control group showed non-canting occlusal plains, whereas when significantly different from the control group showed presence of occlusal plain canting.

Panoramic tracing was done on acetate paper with $0.5 \mathrm{~mm}$ pencil. Then identify NL, ML, and MLa.

Differences in vertical dimensions smaller or equal to $3 \%$ indicate mandible vertical symmetry, whereas greater than $3 \%$ indicates a mandible vertical asymmetry.

The calculation is done once each of 5 samples per day to the total sample. Further assessment was the relation of canting maxillary and mandible plateau between the left and right regions.

\section{RESULTS}

The subjects of this study were 60 adults divided into 3 groups, 20 Skeletal Class I, 20 Skeletal Class II, and 20 Skeletal Class III.

In this study skeletal Class I, II, and III are used to determine the group with the largest skeletal canting and determine whether the dental canting is more prevalent in the left or right region. All data were analyzed using SPSS program. Numerical data is presented in the mean \pm standard deviation.

Canting in skeletal patients Class I, II, and III will be determined using points of identification of is-NL, ms-NL, isa-NL, msa-NL, ii-ML, mi-ML, iia-ML, miaML , ii-MLa, iia-MLa. Measurement of the occlusal plain canting in each sample is the difference between left and right distance measured from is, ms, isa, msa, ii, mi, iia, mia, ii, iia to NL, ML, and MLa plains. (Table I)
TABLE I. COMPARISON BETWEEN THE LEFT AND RIGHT REGIONS BY COMPARING THE POINTS ON THE PANORAMIC RADIOGRAPHY ON SKELETAL CLASS I

\begin{tabular}{|c|c|c|}
\hline Skeletal I & $\begin{array}{c}\text { More extrusion on } \\
\text { right side }\end{array}$ & $\begin{array}{c}\text { More extrusion on } \\
\text { right side }\end{array}$ \\
\hline Is-NL & $52.6 \%$ & $47.4 \%$ \\
\hline Isa-NL & $35.3 \%$ & $64.7 \%$ \\
\hline Ii-ML & $0 \%$ & $100 \%$ \\
\hline Iia-ML & $44.4 \%$ & $55.6 \%$ \\
\hline Ms-NL & $58.8 \%$ & $41.2 \%$ \\
\hline Msa-NL & $44.4 \%$ & $55.6 \%$ \\
\hline
\end{tabular}

Table I is a table of mean values of the calculation of the point measured from the panoramic comparison between the left and right regions, from the results of table 1 in patients with skeletal class I do not look there is a big difference between the left and right only in part Ii-ML which shows the left tooth is more extrusion than the right side.

TABLE II. COMPARISON BETWEEN THE LEFT AND RIGHT REGIONS BY COMPARING THE POINTS ON THE PANORAMIC RADIOGRAPHY ON SKELETAL CLASS II

\begin{tabular}{|c|c|c|}
\hline Skeletal II & $\begin{array}{c}\text { More extrusion on } \\
\text { right side }\end{array}$ & $\begin{array}{c}\text { More extrusion on } \\
\text { right side }\end{array}$ \\
\hline Is-NL & $41.2 \%$ & $58.8 \%$ \\
\hline Isa-NL & $53.3 \%$ & $46.7 \%$ \\
\hline Ii-ML & $61.1 \%$ & $38.9 \%$ \\
\hline Iia-ML & $43.8 \%$ & $56.3 \%$ \\
\hline Ms-NL & $70 \%$ & $30 \%$ \\
\hline Msa-NL & $77.8 \%$ & $22.2 \%$ \\
\hline
\end{tabular}

Table II is a table of mean values of the calculation of point measured from panoramic compared between the left and right regions, from the results of table 2 in patients with skeletal class II seen a large difference between the left and right only where the right region that shows the teeth more extrusion than to the left.

TABLE III. COMPARISON BETWEEN THE LEFT AND RIGHT REGIONS BY COMPARING THE POINTS ON THE PANORAMIC RADIOGRAPHY OF SKELETAL MALOKLUSI CLASS III

\begin{tabular}{|c|c|c|}
\hline Skeletal III & $\begin{array}{c}\text { More extrusion on } \\
\text { right side }\end{array}$ & $\begin{array}{c}\text { More extrusion on } \\
\text { right side }\end{array}$ \\
\hline Is-NL & $61.5 \%$ & $38.5 \%$ \\
\hline Isa-NL & $75 \%$ & $25 \%$ \\
\hline Ii-ML & $76.5 \%$ & $23.5 \%$ \\
\hline Iia-ML & $60 \%$ & $40 \%$ \\
\hline Ms-NL & $75 \%$ & $25 \%$ \\
\hline Msa-NL & $75 \%$ & $25 \%$ \\
\hline
\end{tabular}

Table III is a table of mean values of the calculation of point measured from panoramic compared between the left and right regions, from the results of table 3 in patients with skeletal class III seen a large difference between the left and right only where the right region that shows the teeth more extrusion than to the left.

From the calculation of Chi-Square test in Table IV, the value of Asimp Sig $<0.05$ then $\mathrm{H} 0$ is accepted indicates that there is a significant correlation between canting in patients with skeletal malocclusion Class I, II, and III. Thus, statistically the correlation test results 
obtained a significant difference between canting on Class I, II, and III malocclusions.

TABLE IV. CHI-SQUARE TESTS

\begin{tabular}{|l|c|c|c|}
\hline & Value & df & Asymp. Sig. (2 sided) \\
\hline Pearson Chi-Square & $25.170^{\mathrm{a}}$ & 2 & .000 \\
\hline Likelihood Ratio & 32.746 & 2 & .000 \\
\hline $\begin{array}{l}\text { Linear-By-Linear } \\
\text { Association }\end{array}$ & 22.189 & 1 & .000 \\
\hline N Of Valid Cases & 55 & & \\
\hline
\end{tabular}

a. 0 cells $(.0 \%)$ have expected count less than 5 . The minimum

expected count is 7.42 .

\section{DISCUSSION}

This study was an analytic study using retrospective cross-sectional method to determine the relationship between dentoalveolar canting in skeletal patients Class I, II, and III. The subjects of the study were RSGM FKG USU and FKG USU students without skeletal patients in Class I, II, and III. The results of this study are expected to be a source of information and assist clinicians in diagnosing the presence of dentoalveolar canting in skeletal patients Class I, II, and III so as to prevent the need for more complex care in the future.

The method of measurement carried out in this study was based on the nasila et al method, which introduced the formula of dentoalveolar canting index to assess the point used in determining the height of the tooth between the left and right regions.4 However, in this study, the panoramic patients used were taken from the same place. This is done to obtain the same radiographic quality as the primary basis for proper point enforcement. In addition, distortion and poor quality radiographic films were not included in this study $[3,4]$.

Dental asymmetry may occur due to an imbalance between the number of teeth with available dental arch, an imbalance between the number of maxillary and lower teeth in the same segment. It is present in all types of cases but the most common is in Class II malocclusions. Causes of midline deviation may be: posterior cross bites due to mandible shift, upward or downward anterior teeth movement, mandible lateral shift (no cross bite), asymmetry of dental arch, or combination $[5,6]$.
Haraguchi et al stated that dentoalveolar canting is more common in the mandible because mandible growth lasts longer than the maxilla and thus tends to show more canting. In addition, the mandible is a moveable and functionally adaptive organ, while the maxilla is rigidly connected to the skeletal structure which is adjacent to the sutures and syncrosis $[7,8,9,10]$.

The results of this study reported that there is a significant relationship between dentoalveolar canting on skeletal Class I, II, and III, seen asimp sig value $<0,05$. Hence the hypothesis that there is a difference of dentoalveolar canting on skeletal Class I, II, and III, is accepted.

Dentoalveolar canting is more prevalent in skeletal malocclusion Class II and III, with greater canting size in molar teeth than in anterior teeth.

\section{REFERENCES}

[1] S.I. Bhalajhi, Orthodontic the art and science, $5^{\text {th }}$ Ed., New Delhi: Arya, 2009, pp. 25,179-180,545-562.

[2] S.E. Bishara, P.S. Burkey, J.G. Kharouf, "Dental and facial asymmetries: A review," Angle Orthod., vol. 64, pp. 89-98, 1994.

[3] W.R. Proffit, Contemporary orthodontics, $2^{\text {nd }}$ ed. St. Louis: Mosby Year Book, 1993, p. 226.

[4] N. Nohadani, S. Ruf, "Assessment of vertical facial and dentoalveolar changes using panoramic radiography," European Journal of Orthodontics, vol. 30, pp. 262-268, 2008.

[5] E.M. Tanaka, S. Sato, "Longitudinal alteration of the occlusa plane and development of different dentoskeletal frames during growth," Am. J. Orthod. Dentofacial Orthop., vol. 134, pp. e1e11, 2008.

[6] S.E. Bishara, Text book of orthodontic. Philadelphia: W.B. Saunders, 2001, pp. 109-112, 160-161, 25, 298-300, 532-544.

[7] P. Kambylafkas, "Validity of panoramic radiographs for measuring mandible asymmetry," Angle Orthod., vol. 76, pp. 388-393, 2006

[8] T.M. Graber, "Panoramic radiography in orthodontic diagnosis," Am. J. Orthod. Dentofacial Orthop., vol. 53, pp. 799-821, 1967.

[9] K. Ishizaki, K. Suzuki, T. Mito, E.M Tanaka, S. Sato, "Morphologic, functional, and occlusal characterization of mandible lateral displacement malocclusion," Am. J. Orthod Dentofacial Orthop., vol. 137, pp. e1-e9, 2010.

[10] S.J. Kim, J.Y. Choi, S.H. Baek, "Evaluation of canting correction of the maxillary transverse occlusal plane and change of the lip canting in class III two-jaw orthognathic surgery," Angle Orthodontist, vol. 82(6), pp. 1092-1097, 2012. 